\section{Positive selection causes purifying selection}

IN their support of the neutral mutation hypothesis of molecular evolution, $\mathrm{Li}$ et $a l .{ }^{1}$ oversimplify the views of selectionists and use a specious logic that should not go unchallenged. They assert after $\mathrm{Clark}^{2}$ and Milkman ${ }^{3}$ that "selectionists believe that most nucleotide substitutions are caused by positive darwinian selection" and then using King and Jukes ${ }^{4,5}$ as their authorities argue "in which case the rate of nucleotide substitution in functionally unimportant genes or parts of genes is expected to be relatively lower because the mutations in these regions of DNA would not produce any significant selective advantages".

I believe that the assertion of Li et al. ${ }^{1}$ is an oversimplication. There are molecular evolutionists who are selectionists because they consider natural selection to be a driving force steering protein evolution $^{6-8}$; however, such proponents of darwinian evolution of proteins are quite willing to have neutral substitutions occur at a high rate in pseudogenes, in the third position of the codons when the base changes do not cause amino acid changes ${ }^{8}$, and in general in functionally less important regions of DNA.

The argument of $\mathrm{Li}$ et al. ${ }^{1}$ is specious because it ignores two factors: (1) the time span for molecular evolution above the species level is in millions of years, not hundreds; and (2) the selection, which is positive darwinian selection when it increases the frequency of an allele in an evolving lineage, becomes stabilizing (=purifying or negative) selection after the allele replaces all others in that lineage. When these two factors are considered it follows that the nucleotide substitutions in functionally important parts of genes, as measured in distant pairwise comparisons such as those of $\mathrm{Li} e t$ $a l .{ }^{1}$, could be primarily adaptive substitutions and still yield a slower evolutionary

\section{Matters Arising}

Matters Arising is meant as a vehicle for comment and discussion about papers that appear in Nature. The originator of a Matters Arising contribution should initially send his manuscript to the author of the original paper and both parties should, wherever possible, agree on what is to be submitted. Neither contribution nor reply (if one is necessary) should be longer than 300 words and the briefest of replies, to the effect that a point is taken, should be considered. rate per nucleotide position than the neutral substitutions in functionally less important genes or parts of genes. For the short time span that an adaptive mutation is being fixed in a lineage by the positive darwinian form of natural selection, there could follow a very long time span during which the fixed mutation was maintained by the stabilizing form of natural selection. Thus over the total time span of many millions of years, the average evolutionary rate for such adaptive mutations could be relatively small. Nevertheless, the findings of $\mathrm{Li}$ et al. ${ }^{1}$ on pseudogenes do not exclude the possibility that for certain important categories of base substitutions, for example, those that change amino acids, a relatively large proportion were fixed by selection rather than random drift.

\section{Department of Anatomy,}

MORRIS GOODMAN

Wayne State University

School of Medicine,

Detroit, Michigan 48201, USA 1. Li, W-H, Gojobori, T. \& Nei, M. Nature 292, 237-239
(1981).

2. Clark, B. Science 168, 1009-1011 (1970).

3. Milkman, R. Trends Biochem. Sci. 1, N152-N154 (1976)

4. King, J. L. \& Jukes, T. H. Science 164, 788-798 (1969).

. Jukes, T. H. \& King, J. L. Nature 231, 114-115 (1971).

6. Goodman, M., Moore, G. W. \& Matsuda, G. Nature 253, 603-608 (1975).

7. Goodman, M. \& Czelusniak, J. Protein Biol. Fluids 28, 57-60 (1980)

8. Goodman, M. Prog. Biophys. molec. Biol. 38, 105-164 (1981).

LI ET AL. REPLY-Goodman accepts our view that random fixation of neutral alleles occurs at a high rate in such unimportant genes as pseudogenes or in general in functionally less important regions of DNA, but believes that natural selection is a driving force steering protein evolution. He suggests that a large proportion of amino acid substitutions in proteins are caused by natural selection. It is known, however, that the rate of amino acid substitution is also higher in functionally less important proteins or parts of proteins, as in the case of nucleotide substitution in $\mathrm{DNA}^{1,2}$. For example, fibrinopeptides $\mathrm{A}$ and $\mathrm{B}$, which apparently do not have any biological function except for holding other polypeptides that later form a protein, show a rate of nucleotide (amino acid) substitution as high as that of pseudogenes ${ }^{3,4}$. The fact that amino acid sequence apparently does not affect appreciably fibrinopeptide function, and the mutation rate per nucleotide site is presumably the same for these peptides and pseudogenes, strongly suggests that the amino acid substitutions in fibrinopeptides are mainly due to random fixation of neutral alleles.

In functionally important proteins or parts of proteins, the rate of amino acid substitution is much lower than that in fibrinopeptides ${ }^{1,2}$. The neutralist's explanation for this is that these proteins have strong functional constraints, which cause many new mutations to be eliminated from the population, and only those mutations (amino acid sequences) that are functionally equivalent are incorporated into the genome ${ }^{2}$. In the neutral theory, therefore, the entire set of substitution data from pseudogenes to highly conserved proteins such as histone can be explained by the simple and realistic assumption that the mutation rate is the same for all segments of DNA (genes or parts of genes) but the proportion of fresh mutations eliminated varies with DNA segment and the higher this proportion, the slower the rate of gene substitution. Available data support this view, that is, fresh mutations are known to occur almost at random in the entire coding region of haemoglobin $\mathrm{DNA}^{5}$, and any amino acid substitutions generally occur between two amino acids having similar biochemical properties $^{6.7}$. However, if natural selection is the driving force for protein evolution, it would be difficult to explain the inverse relationship between the functional importance of genes and the rate of gene substitution ${ }^{4}$. Note that the rate of gene substitution due to darwinian selection depends not only on the mutation rate but also on the selection coefficient and population size ${ }^{8}$. In any theory based on selection these three factors must be considered.

Goodman's statement that we have ignored the two factors mentioned by him is unfounded. Our conclusion is based on a study of evolutionary change of genes for $80 \mathrm{Myr}$ and on a due consideration of the effects of mutation, selection and random genetic drift. Note also that neutralists believe that adaptive evolution occurs by positive darwinian selection but a small proportion of gene substitutions is sufficient for this ${ }^{9}$.

\section{WEN-HSIUNG LI TAKASHI GOJOBORI MASATOSHI NEI}

\section{Center for Demographic and}

Population Genetics,

University of Texas at Houston,

Houston, Texas 77030 ,

USA

1. King, J. L. \& Jukes, T. H. Science 164, 788-798 (1969) 2. Kimura, M. \& Ohta, T. Proc. natn. Acad. Sci. U.S.A. 71 , 2848-2852 (1974)

3. Kafatos, F. C. et al. Proc. natn. Acad. Sci. U.S.A. 74, 5618-5622 (1977)

4. Li, W.-H., Gojobori, T. \& Nei, M. Nature 292, 237-239 (1981)

5. Vogel, F. J. molec. Evol. 1, 334-367 (1972).

6. Jukes, T. H. \& King, J. L. Nature 231, 114-115 (1971).

7. Grantham, R. Science 185, 862-864 (1974).

8. Kimura, M, \& Ohta, T. Theoretical Aspects of Population Genetics (Princeton University Press, Princeton, 1971).

9. Nei, M. Molecular Population Genetics and Evolution (North Holland, Amsterdam, 1975). 